\title{
Carriage of Cdt-B Encoding Campylobacter spp., Salmonellaenterica, and Yersinia entercolitica in Patients with Gastroenteritis, Irritable Bowel Syndrome, and Controls
}

\section{Leila Ganji}

Health Reference Laboratory Research Center, Reference Health Laboratory, Ministry of Health and Medical Edcucation

\section{Mohmmad Hassan Shirazi}

Tehran university of medical science,

Masoud Alebouyeh ( $\square$ masoud.alebouyeh@gmail.com )

Shahid Beheshti University of Medical Sciences Pediatric Infections Research Center https://orcid.org/0000-0001-7474-2515

\section{Parisa Eslami}

Milad Hospital

\section{Naser Ebrahim Daryani}

Department of Gastroenterology and Hepatology, Tehran University of Medical Science

\section{Mohammad Rahbar}

Health Reference Laboratory Research Center, Reference Health Laboratory, Ministry of Health and Medical Education

\section{Mohammad Reza Zali}

Research Institute of Gastroenterology and Liver Diseases, Shahid Beheshti University

\section{Research}

Keywords: Enteric pathogens, Irritable Bowel Syndrome, Gastroenteritis, Cytolethal distending toxin

Posted Date: February 16th, 2021

DOl: https://doi.org/10.21203/rs.3.rs-196235/v1

License: (9) This work is licensed under a Creative Commons Attribution 4.0 International License. Read Full License 


\section{Abstract}

Background: Cytolethal distending toxin (Cdt) is one of the bacterial toxins that present in a variety of Gram-negative human pathogens, such as E. coli, Salmonella spp., and Campylobacter spp. CDT composed of three subunits encoded by three adjacent genes, including $c d t A, c d t B$ and $c d t C$. It is approved that $c d t B$ had toxic activity and caused DNA damage of the host cell. Despite its presence in different bacterial species, role of Cdt in acute and chronic infections, such as gastroenteritis and irritable bowel syndrome (IBS), is unclear. To analyze this correlation, we studied the prevalence of $c d t \mathrm{~B}$ among different enteropathogenic bacteria in patients with gastroenteritis and IBS compared with healthy people.

Materials and Methods: In this cross-sectional descriptive study, 230 stool samples were collected from patients with gastroenteritis, IBS, and healthy people. The presence of Cdt-B encoding bacteria, including Escherichia coli, Campylobacterspp., Yersinia entercolitica, Providencia alkalifacience, and Salmonella enterica was examined by polymerase chain reaction. Demographic data and type of disease was collected through interview and a questionnaire.

Results: Out of 230 stool samples, Cdt-B encoding Campylobacterspp. were found in 34.6\% (52/150), $6.25 \%(5 / 80)$, and $4 \%(2 / 50)$ of the patients with gastroenteritis, IBS, and the control group, respectively. Carriage of Cdt-B encoding Salmonella enterica was characterized among 5.3\% (8/150) of the patients with gastroenteritis and $17.5 \%(14 / 80)$ of the IBS patients. Although none of the patients carried $c d t B$ of E. coli and Providencia spp., cdtB of Y. enterocolitica was detected in 1 of the patients with gastroenteritis $(0.6 \%)$. Statistical analysis showed significant correlation between infection with CdtB-encoding Campylobacterspp. and IBS-D subtype. No significant correlation was found between infection with Cdt$B$ encoding bacteria, and other clinical and demographic data.

Conclusions: Our results confirmed relatively higher frequency of Cdt-B encoding bacteria in the intestine of IBS patients and those with gastroenteritis compared with healthy individuals. Regarding the frequency of Cdt-B encoding Salmonella and Campylobacter bacteria, it was proposed that infection with these enteropathogens could be considered as a risk factor for the development or progression of IBS among the Iranian patients. Further studies are needed to establish this involvement.

\section{Introduction:}

Cytolethal distending toxins (CDT) represent an emerging and unique toxin family. CDT is a heterotrimeric $\mathrm{AB} 2$ genotoxin, which consist of $c d t \mathrm{~A}, c d t \mathrm{~B}$ and $c d t \mathrm{C}$. CdtA and $\mathrm{CdtC}$ subunits bind to the host cell membrane, whereas CdtB enters to the cell nucleolus and causes direct DNA damage due to DNase activity [1, 2]. Although CdtB is the most conserved subunit among all CDT-producing bacterial strains, its overall amino acid sequence show diversity between 29 to $91 \%$ among different bacteria $[3,4]$.

CDT was first described in Escherichia coli by Johnson and Lior in the 1980s. Gammaproteobacteria and Epsilonproteobacteria are among main members of Proteobacteria that carry $c d t$, however, its presence in 
Firmicutes, e.g. Clostridioides difficile, was also reported [4-6]. Within the Epsilonproteobacteria, CDT was found in the orders Campylobacterales, specially Campylobacter and Helicobacter species [7].

Many of these Gram-negative bacteria are considered as clinically important human pathogens that are responsible for gastroenteritis [8]. Involvement of these bacteria in development of chronic bowel disorders, such as irritable bowel syndrome (IBS), was reported in different studies [9, 10]. Accordingly, 3$30 \%$ of people with IBS experience their symptoms after an episode of acute gastroenteritis (Postinfectious IBS, PI-IBS) [11].

Currently, no definite virulence factors are characterized in these bacteria in association to PI-IBS. Dysbiosis of the gut microbiota and alteration of microbial population in this organ could accelerate growth of more virulent bacteria, which promote functional disorders through their interaction with the host [12-14]. This interaction and the functional disorder, including chronic abdominal pain and alerted intestinal habits, could occur by unknown bacterial virulence factors $[15,16]$. Increased antibody titers against CdtB of Campylobacter as a only proposed virulence factors have been observed in diarrheadominant form of IBS $[17,18]$. This involvement may cause through cross-reaction of the antibodies with vinculin in the host gut [19-21]. Despite wide distribution of this family of toxins in members of the enteric bacteria, little is known about the prevalence of Cdt-B encoding bacteria, their association with distinct types of IBS (IBS with diarrhea, IBS with constipation, and mixed-types), and promotion or exacerbation of the disease. This study was aimed to assess the presence of $c d t \mathrm{~B}$ gene among different enteric bacteria, including Yersinia entercolitica, Salmonella. enterica, E. coli, Providencia alcalifaciens, Aggregatibacter actinomycetemcomitans, and Campylobacter spp. among patients with IBS and gastroenteritis in compare to healthy people.

\section{Materials And Methods:}

\section{Sample collection:}

This cross-sectional descriptive study was conducted on 230 stool samples that obtained from patients with acute gastroenteritis and IBS. A control group of healthy volunteers (50 samples) was also included in the study. A consent form was filled by all participants. The study was approved by ethical committee of Department of Pathobiology, Tehran university of Medical Sciences, Tehran, Iran (TUMS. Ethics code 92-02-27-22726). Fresh stool samples were collected in clean containers and the samples were immediately transferred to the laboratory under cold chain. Adult patients with functional bowel disorders were interviewed by experienced physicians and fulfilled a questionnaire that was designed according to Rome III criteria for IBS [22]. According to symptoms, they was classified as either diarrhea-predominant (IBS-D), constipation-predominant (IBS-C), or with alternating stool pattern (mixed IBS). Exclusion criteria were included, intestinal disturbance (Celiac disease and lactose intolerance), recent history of hospitalization ( $>24 \mathrm{~h}$ ), antibiotic prescription within the last 3 months, surgery of the gastrointestinal tract, local and systematic inflammatory diseases, defined diet, food allergy, and pregnancy. Healthy controls were selected from people of the same age, who enrolled in routine medical check-ups in the 
hospital. These people reported no history of the gastrointestinal disorders and the exclusion criteria described above.

\section{DNA preparation:}

Total DNA of the samples was extracted using DNA Stool Kit (Bionner, South Korea) according to the manufacturer's instructions. The concentration of DNA was measured by Nanodrop (EppendorfGermany). All DNA extracts were stored at $-20^{\circ} \mathrm{C}$ until use.

\section{Identification of $c d t B$ by PCR:}

In this study, specific primers were designed for characterization of $c d t B$ in Y.entercolitica, S. enterica, $E$. coli, Providencia alcalifaciens, and Aggregatibacter actinomycetemcomitans (Table 1). Accordingly, homology of $c d t B$ were determined using CLC Sequence Viewer v.6.0, and appropriate regions were selected. Amplification of the $c d t B$ were carried out in $25 \mu$ reaction containing $5 \mu /$ of DNA template, 0.5 $\mathrm{mM}$ of each dATP, dGTP, dCTP and dTTP (gene fanavaran, Iran), PCR (10x) buffer (Gene fanavaran, Iran), $0.3 \mu /(10 \mathrm{pmol})$ of each forward and reverse primer, $1 \times$ Tag DNA polymerase buffer (Gene fanavaran, Iran), and $0.2 \mu /(5 \mathrm{U} / \mu)$ of Taq DNA polymerase (Fermentase, Germany). Amplified products were visualized in $1.5 \%$ agarose gels along with a mixed DNA ladder.

Table 1

Primers that were used in this study.

\begin{tabular}{|llll|}
\hline Bacteria & Sequence $\mathbf{( 5}^{\prime} \mathbf{\prime}^{\prime} \mathbf{3}^{\prime} \mathbf{)}$ & $\begin{array}{l}\text { PCR } \\
\text { product } \\
\text { (bp) }\end{array}$ & Reference \\
\hline $\begin{array}{l}\text { Campylobacter } \\
\text { jejuni }\end{array}$ & $\begin{array}{l}\text { GTTGGCACTTGGAATTTGCAAGGC } \\
\text { RTTRAARTCNCCYAADATCATCC }\end{array}$ & 470 & {$[23]$} \\
\hline $\begin{array}{l}\text { Yersinia } \\
\text { entercolitica }\end{array}$ & TAGCAATAGCAAATGGATAG & 376 & $\begin{array}{l}\text { This } \\
\text { study }\end{array}$ \\
\hline $\begin{array}{l}\text { Salmonella } \\
\text { enterica }\end{array}$ & ATCTGCTCTAATTCTTGA & & This \\
\hline $\begin{array}{l}\text { Escherichia coli } \\
\text { TTCTGACCATGATCATCTG }\end{array}$ & AGATTCCAGGTGTATTCATC & 283 & study \\
\hline $\begin{array}{l}\text { Providencia } \\
\text { alkalifacience }\end{array}$ & TTTCCWRCTACHGCATAATC & 178 & $\begin{array}{l}\text { This } \\
\text { study }\end{array}$ \\
\hline
\end{tabular}




\section{Sequencing of PCR products.}

PCR products of each suspected sample were purified using QIA Quick Spin Column (Qiagene, Germany). Then, PCR products were automatically sequenced in Sanger sequencing service. Resulted sequences were aligned and analyzed using Blast, Chromas, and BioEdit software.

\section{Statistical analysis.}

Statistical analysis was performed with SPSS software (Version 23, Co Ltd. Tokyo, Japan). Data were expressed as mean \pm standard deviation for continuous and frequency percentage for nominal and categorical variables. The comparison of qualitative variables between groups analyzed by the Pearson Chi-square test. The results were considered to be significant if $p$-values were $\leq 0.05$.

\section{Results:}

\section{Clinical information of patients and controls.}

Out of 80 patients with IBS, 18 had IBS-D (mean age, $37.55 \pm 3.7$ y), 29 had IBS-C (mean age, $37.26 \pm 2.8$ $\mathrm{y}$ ), and 33 had IBS-M (mean age, $42.68 \pm 2.1 \mathrm{y}$ ). In addition, 150 patients with gastroenteritis (mean age, $41.3 \pm 2.1 \mathrm{y}$ ), and 50 healthy controls (mean age, $37.9 \pm 2.1 \mathrm{y}$ ) were recruited into the study.

The results showed that the prevalence of IBS was significantly higher in women than in men (56/24) ( $p$ $<0.05)$. The commonest subtype of IBS in female patients was IBS-C (86.2\%); while, IBS-M was the most frequent type among males (33.33\%). Diarrhea-predominant IBC was the same in men and women. Anxiety was significantly higher among women in compare to men $(P<0.05)$. Similarly, several other symptoms, including abdominal bloating, cramp, and stress were reported more common in females, which was not statistically significant (Table 2). The most common symptoms associated with constipation in subjects with IBS-C was abdominal bloating (89.65\%), followed by bellyache (75\%), while subjects with IBS-D type felt a higher degree of abdominal cramp $(P=0.01)$. Additionally, there was a significant correlation between IBS-C and IBS-M with anxiety. Anxiety degree was significantly associated with bloating $(P=0.02)$ and abdominal pain in IBS patients $(P<0.01)$. No statistically significant difference was measured between age and IBS disease subtypes. 
Table 2

Frequency of symptoms in patients with IBS and gastroenteritis.

\begin{tabular}{|c|c|c|c|}
\hline \multirow[t]{2}{*}{ Type of symptoms } & IBS-C & IBS-D & IBS-M \\
\hline & $\mathbf{N}(\%)$ & $\mathbf{N}(\%)$ & $\mathbf{N}(\%)$ \\
\hline Total number & $29 / 80(14.5 \%)$ & $18 / 80(22.5 \%)$ & $33 / 80(15.4 \%)$ \\
\hline Anxiety & $21(72.41 \%)$ & $8(44.44 \%)$ & $17(51.51 \%)$ \\
\hline Yes & $8(27.58 \%)$ & $10(55.55 \%)$ & $16(48.48 \%)$ \\
\hline \multicolumn{4}{|l|}{ No } \\
\hline Abdominal pain & $21(72.41 \%)$ & $14(77.77 \%)$ & $27(81.81 \%)$ \\
\hline Yes & $8(27.58 \%)$ & $4(22.22 \%)$ & $6(18.18 \%)$ \\
\hline \multicolumn{4}{|l|}{ No } \\
\hline Abdominal Cramp & $9(31.03 \%)$ & $15(83.33 \%)$ & $17(51.51 \%)$ \\
\hline Yes & $20(68.96 \%)$ & $3(16.66 \%)$ & $16(48.48 \%)$ \\
\hline \multicolumn{4}{|l|}{ No } \\
\hline Abdominal bloating & $26(89.65 \%)$ & $3(16.66 \%)$ & $30(90.9 \%)$ \\
\hline Yes & $3(10.34 \%)$ & $15(83.33 \%)$ & $3(9.09 \%)$ \\
\hline \multicolumn{4}{|l|}{ No } \\
\hline Stress & $22(75.86 \%)$ & $12(66.66 \%)$ & $20(60.6 \%)$ \\
\hline Yes & $7(24.13 \%)$ & $6(33.33 \%)$ & $13(39.39 \%)$ \\
\hline \multicolumn{4}{|l|}{ No } \\
\hline Infection with $\mathrm{CdtB}$ encoding bacteria & $4(13.79 \%)$ & $2(11.11 \%)$ & $8(24.24 \%)$ \\
\hline Salmonella & $1(3.44 \%)$ & $3(16.66 \%)$ & $1(3.03 \%)$ \\
\hline \multicolumn{4}{|l|}{ Campylobacter } \\
\hline Others & & & \\
\hline
\end{tabular}

\section{Diversity ofcdtB gene variants in the fecal DNA extracts}

The frequency of $c d t \mathrm{~B}$ varied between patients with IBS, gastroenteritis, and healthy people. $c d t \mathrm{~B}$ of Campylobacter showed high- frequency in stool samples of patients with gastroenteritis $(34.6 \%, 52 / 150)$; which was higher than those characterized in patients with IBS and healthy people $(6.25 \%, 5 / 80$ and $4 \%$, $2 / 50$, respectively). The difference was statistically significant $(p<0.05)$. Significant association also were seen between $c d t \mathrm{~B}$ of Campylobacterspp. and IBS-D patients. $c d t \mathrm{~B}$ of $S$. enterica was detected in 8 
(5.3\%) and 14 (17.5\%) of the patients with gastroenteritis and IBS, respectively. There was a significant difference between the presence of $c d t \mathrm{~B}$ of $S$. enterica in patients with IBS and gastroenteritis compared with healthy subjects $(p<0.05)$. However, the presence of $c d t B$ of $S$. enterica didn't show a correlation with IBS types $(24.24 \%, 13.79 \%$, and $11.11 \%$ in IBS-M, IBS-C, and IBS-D patients, respectively). $c d t B$ of $E$. coli and $P$. alkalifacience was not detected in any of the patients with IBS, gastroenteritis, and in the control group. The results also indicated that only $0.6 \%$ of the patients with gastroenteritis carried $c d t \mathrm{~B}$ of Y.entercolitica (Table 3). Statistical analyses showed no significant correlation between Cdt-B encoding bacteria and gender or other demographic data among the studied patients with IBS.

Table 3

Presence of $c d t B$ in enteric pathogenic bacteria among patients with Irritable bowel syndrome, gastroenteritis, and controls.

\begin{tabular}{|llllll|}
\hline & P. alkalifaciance & $\begin{array}{l}\text { Y. } \\
\text { entercolitica }\end{array}$ & $\begin{array}{l}\text { E. } \\
\text { coli }\end{array}$ & $\begin{array}{l}\text { S. } \\
\text { enterica }\end{array}$ & $\begin{array}{l}\text { Campylobacter } \\
\text { spp. }\end{array}$ \\
\hline IBS $(\mathrm{n}=80)$ & 0 & 0 & 0 & $\begin{array}{l}14 \\
(17.5 \%)\end{array}$ & $5(6.25 \%)$ \\
\hline $\begin{array}{l}\text { Gastroenteritis }(\mathrm{n}= \\
150)\end{array}$ & 0 & $1(0.6 \%)$ & 0 & $8(5.3 \%)$ & $52(34.6 \%)$ \\
\hline Control $(\mathrm{n}=50)$ & 0 & 0 & 0 & 0 & $3(3.75 \%)$ \\
\hline
\end{tabular}

\section{Sequence accession number}

Nucleotide sequence analysis of related amplified PCR products showed $100 \%$ identity to $c d t B$ of Campylobacter spp., S. enterica and Y. entercolitica. The accession numbers of the sequences of the PCR products submitted to GenBank were as follows: KT008107.1, KR778819.1, KT008106.1 (https://www.ncbi.nlm.nih.gov).

\section{Discussion:}

The overall objectives of the current study were to determine diversity and frequency of $c d t B$ gene among different enteropathogenic bacteria in subjects with IBS and gastroenteritis and their possible roles in the occurrence of these diseases.

According to our results, higher frequency of cdtB of Campylobacterspp. was detected in patients with IBS (6.25\%) and in patients with gastroenteritis (34.6\%), compared with healthy people (3.75\%). Similar to our results, high prevalence of $c d t B$ was detected among Campylobacter isolates in patients with gastroenteritis [25]. Peter KE et al characterized $c d t B$ gene among $67 \%$ of $C$. jejuni and $19 \%$ of $C$. coli isolates in patients with gastroenteritis. In a study by Burliaeva et al, cdtB encoding Campylobacter strains was detected in $5 \%$ of patients with IBS [26], which was relatively similar to our results. In our study, the frequency of Cdt-B encoding Campylobacter spp. was significantly higher among IBS-D patients (16.66\%). The higher frequency of Cdt-B of Campylobacter among patients with the diarrhea 
type disease could be explained through function of Campylobacter CdtB with the intestine. Burliaeva et al showed that wild-type Cdt-B encoding $C$. jejuni strain is able to induce chronic altered bowel patterns and mild chronic rectal inflammation $[25,26]$. Although, new developing commercial diagnostic kits for detection of anti-CdtB antibodies as specific biomarker for diarrhea-predominant irritable bowel syndrome is currently in use by some countries $[17,18]$, further studies are needed to establish whether CdtB positive Campylobacter strains are associated with diarrhea in patients with irritable bowel syndrome. It seems that CDT has the ability to attack the cells of intestinal villi, and cause disease $[27,28]$. In this study, no significant association was seen between the Campylobacter encoding $c d t \mathrm{~B}$ and other clinical symptoms, including abdominal bloating. No significant correlation also was found between Cdt-B encoding Campylobacter spp. and gender among IBS patients, while most of IBS patients were female.

$c d t \mathrm{~B}$ of $S$. enterica was detected in $14 \%$ of patients with IBS and $5.3 \%$ of patients with gastroenteritis in current study, while it was not detectable in the control group. Few studies have been done on Salmonella spp.; however, the presence of $c d t \mathrm{~B}$ in Salmonella is reported both for typhoidal and non-typhoidal $S$. enterica (NTS) serovars [5, 29-32]. In a study by Mezal et al., the carriage of $c d t \mathrm{~B}$ gene was detected among all isolates of Salmonella enterica serovar Javiana isolated from food, environmental, and clinical samples [5]. An increased level of CDT-mediated invasiveness for these isolates was shown in HeLa cell culture, which could support possible involvement of this toxin in different diseases of the gastrointestinal tract. .

Recent evidence demonstrated that $Y$. entercolitica is linked with chronic gastrointestinal diseases, including IBS, dyspepsia, constipation, and Inflammatory bowel disease (IBD) [33]. However, this involvement was not confirmed in our study, since only one Cdt-B encoding $Y$. entercolitica sample was characterized. Similarly, none of the samples of patients with IBS and gastroenteritis, and healthy people were positive for $c d t \mathrm{~B}$ of $E$. coli and $P$. alcalifacience. In a study by Meza-Segura et al, out of 1306 young children with acute diarrhea, $c d t$ encoding E. coli strains detected in $1 \%$ of the patients [34]. In another study, cdtB gene were found in $1.4 \%$ of 366 E. coli strains isolated from stool specimens of patients with acute diarrhea in Calcutta, India [35].

In our study, we didn't find $c d t B$ of $P$. alcalifacience among our samples. However, Shiam et al. detected $c d t \mathrm{~B}$ harboring $P$. alcalifacience among $9.7 \%$ of patients with diarrhea [36]. According to our knowledge, no report for this bacterium and CDT exists in patients with IBS, which is consistent to our finding.

\section{Conclusion:}

Our data showed high distribution of cdtB gene among Campylobacter spp. and Salmonella spp. in stool samples of patients with IBS and gastroenteritis. These findings proposed that infection with CdtB encoding bacteria could be a risk factor for development of IBS. In addition, significant association was seen between CdtB encoding Campylobacter spp. and diarrhea-predominant irritable bowel syndrome. No significant correlation was found between CdtB encoding Campylobacterspp. and S. enterica and gender among the IBS patients. Further studies are needed to establish this correlation. 


\section{Declarations:}

\section{Acknowledgment}

Many thanks go to Prof. Saeid Bouzari (Pasture Institute of Iran, E. coli Reference Laboratory, Iran) for providing DNA of CdtB encoding E. coli.

\section{Ethical approval and consent to participate.}

The study was approved by ethical committee of Department of Pathobiology, Tehran university of Medical Sciences, Tehran, Iran (TUMS. Ethics code 92-02-27-22726).

\section{Consent for publication.}

Not declared

\section{Availability of data and materials.}

All data generated or analyzed during this study are included in this published article.

\section{Competing interests.}

None declared.

\section{Funding:}

This study was supported by Department of Pathobiology, Tehran university of Medical Sciences, Tehran, Iran (92-02-27-22726), Tehran, Iran.

\section{Authors' Contributions.}

Leila Ganji provide the samples and do laboratory tests. Write the manuscript. Parisa Eslami, Dr.

Mohammad Rahbar, and Dr. Nase Ebrahim Daryani provide the clinical samples. Dr. Mohammad Hassan Shirazi advised the project and provide technical helps. Dr. Masoud Alebouyeh designed and supervised the study.

\section{References:}


1. Lara-Tejero Ma, Galán JE: CdtA, CdtB, and CdtC form a tripartite complex that is required for cytolethal distending toxin activity. Infection and immunity. 2001 ; 69(7):4358-4365.

2. Pickett CL, Whitehouse CA: The cytolethal distending toxin family. Trends in microbiology. 1999 ;7(7):292-297.

3. Elwell CA, Dreyfus LA: DNase I homologous residues in CdtB are critical for cytolethal distending toxin-mediated cell cycle arrest. Molecular microbiology. 2000 ; 37(4):952-963.

4. Jinadasa RN, Bloom SE, Weiss RS, Duhamel GE: Cytolethal distending toxin: a conserved bacterial genotoxin that blocks cell cycle progression, leading to apoptosis of a broad range of mammalian cell lineages. Microbiology. $2011 ;$ 157(7):1851-1875.

5. Mezal EH, Bae D, Khan AA: Detection and functionality of the CdtB, PItA, and PltB from Salmonella enterica serovar Javiana. Pathogens and disease. 2014 ; 72(2):95-103.

6. Osek J: Detection of cytolethal distending toxin genes in Shiga toxin-producing Escherichia coli isolated from different sources. Bull Vet Inst Pulawy. $2005 ;$ 49:153-156.

7. Whitehouse CA, Balbo PB, Pesci EC, Cottle DL, Mirabito PM, Pickett CL: Campylobacter jejuni cytolethal distending toxin causes a G2-phase cell cycle block. Infection and immunity. 1998 ; 66(5):1934-1940.

8. Humphries RM, Linscott AJ: Laboratory diagnosis of bacterial gastroenteritis. Clinical microbiology reviews. 2015 ; 28(1):3-31.

9. Schwille-Kiuntke J, Enck P, Zendler C, Krieg M, Polster A, Klosterhalfen S, Autenrieth I, Zipfel S, Frick JS: Postinfectious irritable bowel syndrome: follow-up of a patient cohort of confirmed cases of bacterial infection with Salmonella or Campylobacter. Neurogastroenterology \& Motility. 2011 ; 23(11).

10. Marshall JK, Thabane M, Borgaonkar MR, James C: Postinfectious irritable bowel syndrome after a food-borne outbreak of acute gastroenteritis attributed to a viral pathogen. Clinical Gastroenterology and Hepatology. 2007 ; 5(4):457-460.

11. Thornley JP, Jenkins D, Neal K, Wright T, Brough J, Spiller RC: Relationship of Campylobacter toxigenicity in vitro to the development of postinfectious irritable bowel syndrome. The Journal of infectious diseases. $2001 ; 184(5): 606-609$.

12. Shukla R, Ghoshal U, Dhole TN, Ghoshal UC: Fecal microbiota in patients with irritable bowel syndrome compared with healthy controls using real-time polymerase chain reaction: an evidence of dysbiosis. Digestive diseases and sciences. 2015 ; 60(10):2953-2962.

13. Carding S, Verbeke K, Vipond DT, Corfe BM, Owen LJ: Dysbiosis of the gut microbiota in disease. Microbial ecology in health and disease. $2015 ; 26(1): 26191$.

14. Ganji L, Alebouyeh M, Shirazi MH, Eshraghi SS, Mirshafiey A, Daryani NE, Zali MR: Dysbiosis of fecal microbiota and high frequency of Citrobacter, Klebsiella spp., and Actinomycetes in patients with irritable bowel syndrome and gastroenteritis. Gastroenterology and hepatology from bed to bench. $2016 ; 9(4): 325$. 
15. Chassard C, Dapoigny M, Scott KP, Crouzet L, Del'homme C, Marquet P, Martin JC, Pickering G, Ardid $D$, Eschalier A: Functional dysbiosis within the gut microbiota of patients with constipated-irritable bowel syndrome. Alimentary pharmacology \& therapeutics. $2012 ; 35(7): 828-838$.

16. Chong PP, Chin VK, Looi CY, Wong WF, Madhavan P, Yong VC: The Microbiome and Irritable Bowel Syndrome-A Review on the Pathophysiology, Current Research and Future Therapy. Frontiers in microbiology. 2019; 10:1136.

17. Pimentel M, Morales W, Rezaie A, Marsh E, Lembo A, Mirocha J, Leffler DA, Marsh Z, Weitsman S, Chua KS: Development and validation of a biomarker for diarrhea-predominant irritable bowel syndrome in human subjects. PLoS One. $2015 ;$ 10(5).

18. Buff E: A diagnostic blood test for irritable bowel syndrome: a utopia? Revue medicale suisse. 2015; 11(484):1628.

19. Pimentel M, Morales W, Pokkunuri V, Brikos C, Kim SM, Kim SE, Triantafyllou K, Weitsman S, Marsh Z, Marsh E: Autoimmunity links vinculin to the pathophysiology of chronic functional bowel changes following Campylobacter jejuni infection in a rat model. Digestive diseases and sciences. 2015; 60(5):1195-1205.

20. Schmulson M, Balbuena R, de Law CC: Clinical experience with the use of anti-CdtB and anti-vinculin antibodies in patients with diarrhea in Mexico. Revista de Gastroenterología de México (English Edition). 2016 ; 81(4):236-239.

21. Pimentel $M$, Chang $C$ : Methods of comparing anti-vinculin and anti-cytolethal distending toxin antibodies as they relate to irritable bowel syndrome. In.: Google Patents; 2017.

22. Whitehead WE, Drossman DA: Validation of symptom-based diagnostic criteria for irritable bowel syndrome: a critical review. The American journal of gastroenterology. $2010 ; 105(4)$.

23. Bang DD, Nielsen EM, Scheutz F, Pedersen K, Handberg K, Madsen M: PCR detection of seven virulence and toxin genes of Campylobacter jejuni and Campylobacter coli isolates from Danish pigs and cattle and cytolethal distending toxin production of the isolates. Journal of applied microbiology. 2003; 94(6):1003-1014.

24. Pickett CL, Pesci EC, Cottle DL, Russell G, Erdem AN, Zeytin H: Prevalence of cytolethal distending toxin production in Campylobacter jejuni and relatedness of Campylobacterspp. cdtB gene. Infection and Immunity. 1996; 64(6):2070-2078.

25. Peters KE, Chang Y-C, Duhamel GE, Sultan AA, Doiphode S, Ibrahim EM, Mohammed HO: Cytolethal Distending Toxin in Salmonella and Campylobacterspp. Isolated from Food Animals and Gastroenteritis Cases in Qatar. Global Journal of Health Science. 2017; 9(10).

26. Burliaeva E, Bulakhov A, Pilipenko V, Isakov V, Sheveleva S: Campylobacter in stool of patients with irritable bowel syndrome. Eksperimental'naia i klinicheskaia gastroenterologiia Experimental \& clinical gastroenterology. 2010; 53-57.

27. Pokkunuri V, Pimentel M, Morales W, Jee S-R, Alpern J, Weitsman S, Marsh Z, Low K, Hwang L, Khoshini R: Role of cytolethal distending toxin in altered stool form and bowel phenotypes in a rat 
model of post-infectious irritable bowel syndrome. Journal of neurogastroenterology and motility. 2012; 18(4):434.

28. Scuron MD, Boesze-Battaglia K, Dlakić M, Shenker BJ: The cytolethal distending toxin contributes to microbial virulence and disease pathogenesis by acting as a tri-perditious toxin. Frontiers in cellular and infection microbiology. 2016; 6:168.

29. Miller R, Wiedmann M: Dynamic Duo-The Salmonella Cytolethal Distending Toxin Combines ADPRibosyltransferase and Nuclease Activities in a Novel Form of the Cytolethal Distending Toxin. Toxins. 2016 ; 8(5):121.

30. Haghjoo E, Galán JE: Salmonella typhi encodes a functional cytolethal distending toxin that is delivered into host cells by a bacterial-internalization pathway. Proceedings of the National Academy of Sciences. 2004 ; 101(13):4614-4619.

31. Rodriguez-Rivera LD, Bowen BM, den Bakker HC, Duhamel GE, Wiedmann M: Characterization of the cytolethal distending toxin (typhoid toxin) in non-typhoidal Salmonella serovars. Gut pathogens. $2015 ; 7(1): 19$.

32. Williams K, Gokulan K, Shelman D, Akiyama T, Khan A, Khare S: Cytotoxic mechanism of cytolethal distending toxin in nontyphoidal Salmonella serovar (Salmonella Javiana) during macrophage infection. DNA and cell biology. 2015; 34(2):113-124.

33. Porter CK, Choi D, Cash B, Pimentel M, Murray J, May L, Riddle MS: Pathogen-specific risk of chronic gastrointestinal disorders following bacterial causes of foodborne illness. BMC gastroenterology. 2013;3(1):46.

34. Meza-Segura M, Zaidi MB, Maldonado-Puga S, Huerta-Cantillo J, Chavez-Dueñas L, Navarro-Garcia F, Estrada-Garcia T: Cytolethal distending toxin-producing Escherichia coli strains causing severe diarrhoea in young Mexican children. JMM case reports. 2017; 4(2).

35. Pandey M, Khan A, Das SC, Sarkar B, Kahali S, Chakraborty S, Chattopadhyay S, Yamasaki S, Takeda $Y$, Nair GB: Association of cytolethal distending toxin locus cdtB with enteropathogenic Escherichia coli isolated from patients with acute diarrhea in Calcutta, India. Journal of clinical microbiology. 2003; 41(11):5277-5281.

36. Shima A, Hinenoya A, Asakura M, Sugimoto N, Tsukamoto T, Ito H, Nagita A, Faruque SM, Yamasaki S: Molecular characterizations of cytolethal distending toxin produced by Providencia alcalifaciens strains isolated from patients with diarrhea. Infection and immunity. 2012; 80(4):1323-1332. 